\title{
Introducción al Dossier: “A 50 años del Cordobazo. Repensando el ciclo de protestas obreras, rebeliones populares e insurrecciones urbanas" ${ }^{\prime *}$
}

\author{
[Introduction to the Dossier: "To 50 Years of the Cordobazo. \\ Rethinking the Cycle of Labor Protests, Popular Rebellions, and Urban \\ Insurrections"]
}

Laura Valdemarca

(Centro de Investigaciones de la Facultad de Filosofía y HumanidadesUniversidad Nacional de Córdoba) lau.valdemarca@gmail.com

Gabriel Fernando Carini

(Centro de Investigaciones Históricas-Universidad Nacional de Río

Cuarto/ISTE-CONICET)

gcarini@hum.unrc.edu.ar

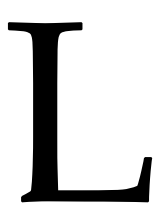

os acontecimientos del 29 y 30 de mayo de 1969 constituyeron una bisagra en la historia argentina que, por un lado, aceleraron una salida electoral al gobierno de Onganía y, por otro lado, abrieron un ciclo de protestas en toda la cartografía del país que anticipaba la dinámica caracterizada por la radicalización política por la que se iba a transitar durante la década de 1970. El Cordobazo -como rápidamente se lo denominó- fue objeto de lecturas inmediatas construidas desde las herramientas conceptuales de la sociología que procuraban otorgar inteligibilidad a lo acontecido. Estas interpretaciones -con diferentes matices- recorrían las reflexiones desde dos claves explicativas: por un lado, enfatizaban en una mirada estructural de las contradicciones presentes en la estructura socio-económica de la sociedad cordobesa cimentadas a lo largo del tiempo y que encontraron cauce en los episodios de mayo de 1969.

\footnotetext{
${ }^{*}$ Los coordinadores del dossier desean agradecer al equipo editorial del Anuario de la Escuela de Historia Virtual por el riguroso trabajo realizado. Asimismo, hacen extensivo el reconocimiento a los autores y evaluadores de los artículos.
} 
Por el otro lado, remarcaban el análisis de la coyuntura señalando que la protesta había constituido una respuesta tanto a las políticas de racionalización económica implementadas por el ministro Krieger Vasena, como al autoritarismo del gobierno que imposibilitaba la solución del conflicto dentro de los canales institucionales. Más allá de las tonalidades de estas explicaciones, en ambas miradas cobraba centralidad la idea de enfatizar la singularidad de la cultura política cordobesa en general y de su movimiento obrero en particular como factor explicativo de la protesta. ${ }^{1}$

Prácticamente al calor de aquellas disputas, los textos de Juan Carlos Agulla y de Francisco Delich, aparecidos casi de inmediato, iniciaron el camino de convertir al hecho histórico en material de análisis académico, sin desmedro de auspiciar las discusiones políticas de la época. ${ }^{2}$ El oscurantismo posteriormente impuesto por la dictadura entre 1976 y 1983 clausuró todo debate hasta los años ochenta. Ya en esa década, sin mayores variaciones, aquellas claves explicativas también permearon la compresión de los análisis sociológicos. ${ }^{3}$ Fueron los aportes realizados desde el campo de la historia durante la mitad de la década siguiente los que posibilitaron avanzar hacia miradas más integrales del fenómeno. Particularmente, los de James Brennan y Mónica Gordillo revisaron sentidos comunes que esa producción contribuyó a consolidar y avanzaron en una explicación que combinó un exhaustivo marco heurístico con elementos conceptuales de la teoría de la acción colectiva que les permitieron explicar la radicalización vivida entre fines de los años sesenta y setenta en la ciudad de Córdoba. ${ }^{4}$

Más allá de este devenir, lo incuestionable es que el Cordobazo se constituyó en un hecho liminar. En este sentido, el quincuagésimo aniversario nos interpeló sobre la necesidad de volver a poner en tensión, revisitar y discutir interpretaciones predominantes especialmente al calor de la agenda historiográfica actual abierta a explorar cuestiones de género, las juventudes, el juego de escalas y la opción por los contextos múltiples, entre otros. Así, el Cordobazo constituye un caleidoscopio privilegiado para analizar múltiples problemáticas históricas. Resultado de esa inquietud, presentamos este dossier que reúne una serie de trabajos que sintetizan parte las discusiones desarrolladas en las Jornadas “A 50 años del Cordobazo. Repensando el ciclo de protestas obreras, rebeliones populares e insurrecciones urbanas". ${ }^{5}$

\footnotetext{
${ }^{1}$ Un recorrido por estas miradas se encuentra en Gordillo (1994).

2 Entre los más paradigmáticos, se encuentran los trabajos de Agulla (1969) y Delich (1970).

${ }^{3}$ Ver, entre otros, Bravo Tedín y Sarría (1989); Balvé y Balvé (1989).

${ }^{4}$ Nos referimos a las tesis de doctorado en Historia presentadas en la Universidad de Harvard por James Brennan y en la Universidad Nacional de Córdoba por Mónica Gordillo y que fueron publicadas como Brennan (1996) y Gordillo (1996). Posteriormente, los autores avanzaron en una revisión de sus perspectivas (Brennan y Gordillo, 2008).

${ }^{5}$ Las jornadas se llevaron a cabo en el campus de la Universidad Nacional de Córdoba y fueron organizadas conjuntamente por el Centro de Investigaciones María Saleme de Burnichon (CIFFyH-UNC), el Instituto de Humanidades (IDH-CONICET-UNC), la cátedra de Historia Argentina II de la Escuela de Historia y la cátedra de Historia Social Argentina del Departamento de Antropología, ambas de la Facultad de Filosofía y Humanidades de la UNC. Recibieron el aval institucional de las mencionadas unidades académicas y fueron declaradas de interés institucional por resolución rectoral 295/2019.
}

Anuario de la Escuela de Historia Virtual - Año 10 - N 16 - 2019: pp. 51-55. ISSN: 1853-7049 
Los trabajos aquí reunidos recorren tres dimensiones. En primer lugar, se encuentra presente la intención de explorar, desde diferentes territorialidades, las experiencias de articulación desarrolladas por la militancia política y, de esta forma, explorar, por ejemplo, acciones diferentes a la acción sindical y de los sindicatos líderes en las experiencias de radicalización. En este marco, se inscribe el artículo de Ernesto Roland, “El Partido Socialista de la Izquierda Nacional (PSIN) de Córdoba y su participación en el Cordobazo". El autor se dedica a mostrar algunas de las derivas de una izquierda nacional como su raigambre y posición ideológica y su vinculación con el episodio que analizamos en las Jornadas a 50 años del Cordobazo. Es interesante, como resalta el autor, la postura de esta izquierda nacional de separarse tanto del peronismo como de la izquierda tradicional hasta entonces, el Partido Comunista y el Partido Socialista y generar una posición diferenciada- según ellos - acorde a las necesidades políticas de los tiempos que les circundaban. Los orígenes de esa izquierda al menos en Buenos Aires son bastante conocidos, pero no lo eran en espacios subnacionales. En este punto, es aquí donde el análisis cobra relevancia, puesto que busca mostrar las posibilidades de esta izquierda postuladora de una alianza entre la clase obrera y la clase media en la Córdoba docta e industrial. Esa izquierda nacional, cuyo líder más reconocido era Abelardo Ramos, se nutrió en Córdoba con personalidades del saber académico y de hecho tuvo su mayor inserción en la Universidad Nacional de Córdoba. Algunas de las limitaciones de los vínculos con otros espacios, como el fabril, llevaron a la versión cordobesa de esa izquierda a enfatizar su arraigo en los claustros universitarios más permeables, por entonces, que las fábricas a planteos de este tipo, quedando más o menos en evidencia la dificultad del arraigo de la izquierda en el ámbito sindical.

Una segunda dimensión presente en los trabajos es aquella atravesada por las diferencias de género en torno a las demandas laborales, su traducción en la participación sindical, así como su expresión en la protesta social y en los procesos de radicalización de la militancia. En esa perspectiva, Ana Noguera en “Cartografías femeninas. Un acercamiento al mundo del trabajo con perspectiva de género. Córdoba, 1960-1970" pone en diálogo diversas fuentes que dan cuenta de los procesos de transformación socio-económicos de la segunda mitad del siglo XX. La selección de fuentes resulta sugerente, dado que constituyen miradas que desde múltiples perspectivas (estatales y académicas) describen la situación de las mujeres cordobesas en tiempo del Cordobazo. Primero, retoma el informe sobre Situación de la mujer que trabaja, en la provincia de Córdoba de Elias Baracat, director de Planeamiento de la provincia de Córdoba, que le posibilitan mostrar una estructura del mercado laboral cordobés marcado -a similitud de lo acontecido a nivel nacional- por una fuerte división sexual del trabajo. En segundo lugar, retoma las conclusiones expuestas por la socióloga cordobesa Eva Chamorro Greca en el VIII Curso de Temporada titulado, en esa oportunidad, "La mujer argentina y latinoamericana". En ese punto, describe las implicancias sociales de la "mujer que trabaja" como reflejo de una economía en cambio. Por último, en tercer lugar, analiza la "Nómina de personas de Córdoba desaparecidas y asesinadas en los '70". A partir de esta, señala, sobre un entramado 
altamente heterogéneo de situaciones, un péndulo que oscilaba diferenciando (hetero)sexualmente los espacios laborales de las y los militantes. También el artículo de Rodolfo Laufer "Clase y género en la Córdoba combativa. Las obreras de ILASA y la ocupación de la fábrica en 1970" visita un lugar poco trabajado como es la situación fabril de las mujeres. En Córdoba, como en otros sitios de la industria automotriz, se buscaba la mano de obra femenina para las tareas complementarias en la fabricación de automóviles, los salarios eran menores que en el caso de los hombres y carecían de una tradición de lucha; pero los años sesenta, como parte de la visibilización y la experiencia subjetiva de empoderamiento vivida por diversas "minorías", permitieron a las jóvenes trabajadoras de la Industria Latinoamericana de Accesorios S.A. (ILASA/Córdoba) movilizarse para mejorar sus condiciones de trabajo. Eso irremediablemente condujo a la represión por parte de la patronal ayudada por las fuerzas de seguridad y a la incomprensión, en un principio, de los sectores sindicalizados donde el componente masculino era predominante: el SMATA, Sindicato de Mecánicos y Afines del Transporte Automotor. El autor demuestra las tempranas redes que hoy denominaríamos sororidad, pero que por entonces carecían de calificativo, que generaron estas trabajadoras para cuidarse de las formas de represión en las cuales la condición de género las volvía vulnerables, como la violación. Las jóvenes trabajadoras fabriles pudieron así participar de las protestas e ir adquiriendo una conciencia de clase que les permitió disputar ese lugar en un mundo de prácticas masculinizadas.

Finalmente, una tercera dimensión es la que pone en consideración la historicidad del fenómeno de la represión, que permite, entre otras cuestiones, observar líneas de continuidad no solo en las respuestas represivas, sino también en las formas de procesar socialmente esa violencia. En ese marco, la investigación de Ana Carol Solís, “Organizar la solidaridad contra la represión en Córdoba, un balance provisorio", propone un completo panorama sobre el conocimiento que desde las ciencias sociales en general y la historia en particular se viene realizando respecto a los mecanismos mediante los cuales diferentes actores colectivos organizaron diversas instancias para dar respuesta a la represión durante el poscordobazo. Resulta interesante destacar la incorporación en ese recorrido de lo producido al respecto por las agencias estatales dado que muestra cómo las políticas de memoria pueden orientar la agenda historiográfica y habilitar nuevos sentidos sobre las temáticas abordadas. Asimismo, otra operación sugerente es el llamado que el artículo realiza en torno a la posibilidad de repensar periodizaciones a partir de un caso concreto -como el del Córdoba-, pero en diálogo con las contribuciones que se vienen realizando en otras espacialidades. Por su parte, Marianela Scocco en "De los consejos de guerra al Camarón. Respuestas represivas a las protestas sociales (1969-1973)" analiza la institucionalización de las funciones represivas estatales a través de dos mecanismos: los consejos de guerra y la creación de la Cámara Federal Penal o Camarón, como los coetáneos dieron en llamarla. Scocco demuestra cómo el aparato represor cuidó de enmarcar el disciplinamiento en una legalidad construida ad-hoc, que exacerbó las prácticas de control sobre la militancia, sin discriminar el género del inculpado. Estos mecanismos 
permitieron evadir la obligación estatal de preservar las garantías constitucionales para los 'reos', de modo que las actuaciones fueran rápidas e inapelables. Se generó un aparato institucional que vino a legalizar la represión, sin perjuicio de la represión paraestatal e ilegal con la que pudiera convivir, combinando mecanismos militares y civiles para optimizar los tiempos de la justicia. Dichos mecanismos no fueron desmantelados en el corto período democrático iniciado en 1973.

\section{Referencias bibliográficas}

Agulla, J. C. (1969). Diagnóstico social de una crisis. Córdoba, mayo de 1969. Buenos Aires: Editel.

Balvé, B. y Balvé, B. (1989). El '69. Huelga política de masas. Rosariazo-Cordobazo-Rosariazo. Buenos Aires: Contrapunto.

Bravo Tedín, M. y Sarría, G. (1989). El Cordobazo, un grito de libertad. La Rioja: Editora del Noroeste.

Brennan, J. (1996). El cordobazo. Las guerras obreras en Córdoba 1955-1976. Buenos Aires: Sudamericana.

Brennan, J. y Gordillo, M. (2008). Córdoba rebelde. El cordobazo, el clasismo y la movilización social. La Plata: De la Campana.

Delich, F. (1970). Crisis y protesta social. Córdoba, mayo de 1969. Buenos Aires: Ediciones Signos.

Gordillo, M (1994). El “Cordobazo” en la producción bibliográfica. Estudios, 4, 254-262. DOI: https://doi.org/10.31050/1852.1568.n4.14339

Gordillo, M. (1996). Córdoba en los '60. La experiencia del sindicalismo combativo. Córdoba: Dirección General de Publicaciones de la Universidad Nacional de Córdoba.

Para citar este artículo:

Valdemarca, Laura y Carini, Gabriel Fernando (2019). Introducción al Dossier: "A 50 años del Cordobazo. Repensando el ciclo de protestas obreras, rebeliones populares e insurrecciones urbanas". Anuario de la Escuela de Historia Virtual, 16, 51-55. 